\title{
Analisis Bifurkasi Persamaan Longitudinal pada Gerak Roket Tiga Dimensi Tipe RKX-Lapan
}

\author{
Ndaru Atmi Purnami \\ Program Studi Teknik Elektro, Institut Teknologi Dirgantara Adisutjipto, Yogyakarta \\ email: ndaru.atmi@itda.ac.id
}

\begin{abstract}
This article discusses about longitudinal equation for the three dimensional rocket motion of RKX-Lapan. The RKX-Lapan's rocket is guided rocket which was designed using two phases, boosting and sustaining. The rocket has six degrees of freedom movement. The freedom movements consists of three translational motions and three rotational motions which causess unstable rocket movement. Therefore, stable rocket motion system is needed. The rocket motion system is three dimensional of nonlinear equation, thus linearization process of rocket motion equation is requaired. One of this linearization process is longitudinal motion which consists of two translational motions and one rotational motion. The equation of longitudinal motion has stabilization system analysist on sustaining phase. Bifurcation analysis of longitudinal equation for the three dimensional rocket motion of RKX-Lapan has been created in this article. It determined equilibria and its equation stability character. Furthermore, bifurcation analysist on equilibria and numerical simulation have been done to find out that bifurcation value indicated a topologically nonequivalent.
\end{abstract}

Keywords - Bifurcation, Longitudinal Equation, RKX-Lapan.

\section{Pendahuluan}

Roket RKX-LAPAN merupakan salah satu roket yang disiapkan untuk menjadi guided missile (peluru kendali) [1]. Roket ini didesain dengan menggunakan dua stage (fase), yaitu boosting dan sustaining. Pada roket kendali terdapat gaya dorong, sistem penargetan, dan sistem pengendalian [2]. Sistem kendali roket dapat bekerja dengan baik, apabila semua subsistem mampu bersinergi secara maksimal, sehingga mampu mencapai hasil yang diharapkan [2]. Kriteria sistem gerak roket dikatakan stabil jika sistem kendali roket dapat bekerja dengan baik [2].

Secara umum, roket memiliki enam derajat kebebasan gerak (six freedom of degree) yang terdiri dari tiga gerak translasi dan tiga gerak rotasi, sehingga memungkinkan roket bergerak tidak stabil [3]. Untuk itu, diperlukan sistem gerak roket yang stabil. Sistem gerak roket merupakan persamaan nonlinear tiga dimensi, sehingga diperlukan proses linearisasi persamaan gerak roket. Proses linearisasi terdiri dari dua bagian, yaitu gerak longitudinal dan gerak lateral-directional [3].

Analisis kestabilan persamaan gerak roket tiga dimensi RKX-Lapan sudah ada yang meneliti. Salah satunya adalah artikel yang ditulis oleh [2]. Pada artikel tersebut membahas tentang linearisasi persamaan nonlinear gerak roket serta analisis kestabilan sistem pada fase sustaining menggunakan kriteria kestabilan Routh-Hurwitz. Kemudian dilakukan uji kestabilan dari sistem persamaan gerak roket. Parameter yang digunakan dalam uji kestabilan ini adalah parameter roket RKX-LAPAN yang dianalisis pada kondisi kecepatan terbang yang bervariasi. Dari penelitian tersebut diperoleh kesimpulan bahwa pada kecepatan mach 0.2 , mach 0.5 , mach 1.0 sistem persamaan gerak roket dikatakan stabil, sedangkan pada kecepatan diatas mach 1.0 sistem dikatakan tidak stabil.

Dari sini, diketahui bahwa penentuan parameter kecepatan dalam kestabilan sistem persamaan gerak roket diperoleh dengan metode trial and error, sehingga diperlukan metode 
pasti dalam penentuan parameter kecepatan sebagai batas perubahan kestabilan sistem gerak roket. Metode pasti ini, salah satunya dapat dilakukan dengan analisis bifurkasi. Pada penelitian ini akan dibahas analisis bifurkasi pada titik ekuilibrium hasil penelitian [2] dan dilakukan simulasi numerik, sehingga diperoleh parameter bifurkasi yang menunjukkan ketidakekuivalenan secara topologis dalam hal kestabilan titik ekuilibrium tersebut. Analisis bifurkasi dilakukan pada persamaan longitudinal pada gerak roket terlebih dahulu. Untuk persamaan lateral-directional dapat digunakan sebagai penelitian berikutnya. Oleh karena itu, analisis bifurkasi persamaan longitudinal pada gerak roket tiga dimensi tipe RKX-Lapan menarik untuk dikaji lebih lanjut.

\section{Metode Penelitian}

Berikut diberikan diagram alir tentang metode penelitian yang dilakukan.

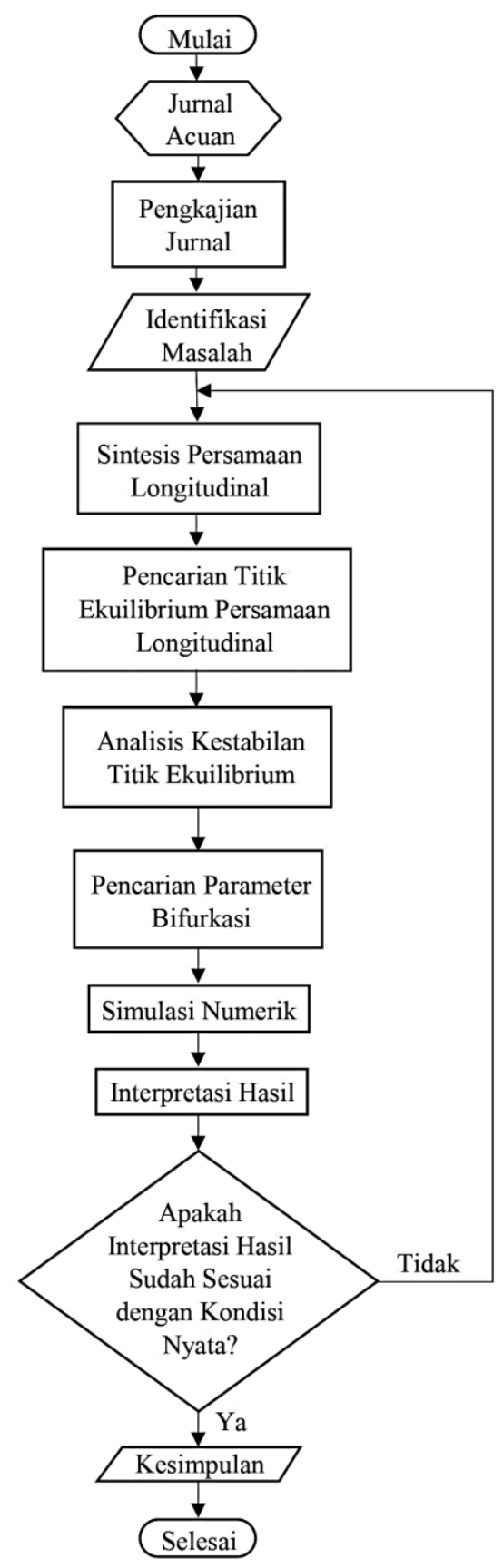

Gambar 1. Diagram Alir Penelitian 
Gambar 1 menunjukkan pada langkah awal dilakukan pengkajian terhadap artikel yang ditulis oleh [2]. Secara umum isi artikel tersebut mengenai analisis kestabilan persamaan gerak roket tiga dimensi tipe RKX-Lapan. Setelah dilakukan pengkajian artikel, dilakukan pembahasan ulang mengenai persamaan longitudinal pada gerak roket tiga dimensi tipe RKXLapan. Pembahasan yang dimaksud yaitu sintesis persamaan longitudinal untuk mendapatkan parameter bifurkasi.

Pada persamaan longitudinal tersebut, titik ekuilibrium sudah dicari oleh [2]. Kemudian [2] sudah menganalisis eksistensi dan sifat kestabilan lokalnya. Cara mencari titik ekuilibrium dan sifat kestabilan tersebut dapat dilihat pada [4-6]. Dari penemuan [2] ini, selanjutnya dilakukan analisis bifurkasi untuk menentukan parameter bifurkasi yang menunjukkan ketidakekuivalenan secara topologis. Untuk definisi dan teorema yang digunakan sebagai acuhan analisis bifurkasi dapat dilihat pada [7-9]. Dan yang terakhir dilakukan simulasi numerik pada model dengan software matlab [10]. Pengambilan data untuk simulasi ini dilakukan secara kualitatif. Hasil dari simulasi numerik ini menunjukkan ketidakekuivalenan secara topologis berupa potret fase yang menunjukkan kestabilan lokal titik ekuilibrium persamaan longitudinal pada gerak roket tiga dimensi tipe RKX-Lapan.

\section{Hasil dan Pembahasan} berikut.

Dari artikel yang ditulis oleh [2] diperoleh persamaan gerak longitudinal sebagai

$$
\begin{aligned}
\Delta \dot{u}= & F_{x_{u}} \Delta u+F_{x_{w}} \Delta w-g \Delta \theta+F_{x_{\delta_{e}}} \Delta \delta_{e} \\
\Delta \dot{w}= & F_{z_{u}} \Delta u+F_{z_{w}} \Delta w+u_{0} \Delta q+F_{z_{\delta_{e}}} \Delta \delta_{e} \\
\Delta \dot{q}= & \left(M_{u}+M_{\dot{w}} F_{z_{u}}\right) \Delta u+\left(M_{w}+M_{\dot{w}} F_{z_{w}}\right) \Delta w+\left(M_{q}+M_{\dot{w}} u_{0}\right) \Delta q \\
& +\left(M_{\delta_{e}}+M_{\dot{w}} F_{z_{e}}\right) \Delta \delta_{e} \\
\Delta \dot{\theta}= & \Delta q
\end{aligned}
$$

dengan parameter yang digunakan akan diberikan pada Tabel 1 sebagai berikut.

Tabel 1. Parameter yang digunakan

\begin{tabular}{c|c|l}
\hline No. & Parameter yang Digunakan & \multicolumn{1}{c}{ Keterangan } \\
\hline 1. & $u$ & Kecepatan linear sumbu-x \\
\hline 2. & $w$ & Kecepatan linear sumbu-z \\
\hline 3. & $q$ & Kecepatan sudut sumbu-y \\
\hline 4. & $\theta$ & Perubahan sudut euler sumbu-y \\
\hline 5. & $F$ & Gaya \\
\hline 6. & $M$ & Momen aerodinamik sumbu-y \\
\hline 7. & $g$ & Percepatan gravitasi bumi \\
\hline 8. & $\delta_{e}$ & Gangguan \\
\hline
\end{tabular}

Dari Persamaan (1) - (4) diperoleh state space persamaan longitudinal [2] berikut. 


$$
\left[\begin{array}{c}
\Delta \dot{u} \\
\Delta \dot{w} \\
\Delta \dot{q} \\
\Delta \dot{\theta}
\end{array}\right]=\left[\begin{array}{cccc}
F_{x_{u}} & F_{x_{w}} & 0 & -g \\
F_{z_{u}} & F_{z_{w}} & u_{0} & 0 \\
\widetilde{M_{u}} & \widetilde{M_{w}} & \widetilde{M_{q}} & 0 \\
0 & 0 & 1 & 0
\end{array}\right]\left[\begin{array}{c}
\Delta u \\
\Delta w \\
\Delta q \\
\Delta \theta
\end{array}\right]+\left[\begin{array}{c}
F_{x_{\delta_{e}}} \\
F_{z_{e}} \\
\left(M_{\delta_{e}}+M_{\dot{w}} F_{z_{\delta_{e}}}\right) \\
0
\end{array}\right]\left[\Delta \delta_{e}\right]
$$

dengan : $\widetilde{M_{u}}=M_{u}+M_{\dot{w}} F_{z_{u}}$;

$$
\begin{aligned}
& \widetilde{M_{w}}=M_{w}+M_{\dot{w}} F_{z_{w}} ; \\
& \widetilde{M_{q}}=M_{q}+M_{\dot{w}} u_{0} .
\end{aligned}
$$
berikut [2].

Dari Persamaan (5) diperoleh titik ekuilibrium persamaan gerak longitudinal sebagai

$$
\begin{aligned}
& \Delta \mathrm{q}=0 \\
& \Delta \mathrm{u}=\frac{-\left(M_{w}+M_{\dot{w}} F_{z_{w}}\right) F_{z_{\delta_{e}}} \Delta \delta_{e}+\left(M_{\delta_{e}}+M_{\dot{w}} F_{z_{e}}\right) F_{w} \Delta \delta_{e}}{\left(M_{w}+M_{\dot{w}} F_{z_{w}}\right) F_{z_{u}}-\left(M_{u}+M_{\dot{w}} F_{z_{u}}\right) F_{z_{w}}} \\
& \Delta \mathrm{w}=\frac{-\left(M_{\delta_{e}}+M_{\dot{w}} F_{z_{e}}\right) F_{z_{u}} \Delta \delta_{e}+\left(M_{u}+M_{\dot{w}} F_{z_{u}}\right) F_{z_{\delta_{e}}} \Delta \delta_{e}}{\left(M_{w}+M_{\dot{w}} F_{z_{w}}\right) F_{z_{u}}-\left(M_{u}+M_{\dot{w}} F_{z_{u}}\right) F_{z_{w}}} \\
& \Delta \theta=\frac{F_{x_{u}} \Delta u+F_{x_{w}} \Delta w+F_{x_{\delta_{e}}} \Delta \delta_{e}}{g}
\end{aligned}
$$

Titik ekuilibrium persamaan gerak longitudinal tersebut dikatakan stabil jika [2]

1. $\left(\widetilde{M_{q}}+F_{z_{w}}+F_{x_{u}}\right)<0$

2. $\left(\widetilde{M}_{q}^{2}-F_{x_{w}} F_{z_{u}}\right)\left(F_{x_{u}}+F_{z_{w}}\right)+\left(F_{x_{u}}{ }^{2}-\widetilde{M_{w}} u_{0}\right)\left(F_{z_{w}}+\widetilde{M_{q}}\right)$

$$
<\widetilde{M_{u}}\left(F_{x_{w}} u_{0}-g\right)-F_{z_{w}}{ }^{2}\left[\left(\widetilde{M_{q}}+F_{x_{u}}\right)+\frac{2 F_{x_{u}} \widetilde{M_{q}}}{F_{z_{w}}}\right]
$$

3. $F_{z u} \widetilde{M_{w}}>F_{z_{w}} \widetilde{M_{u}}$

4. $\left[\left(F_{z_{w}}\left(\widetilde{M_{q}}+F_{x_{u}}\right)-\widetilde{M_{w}} u_{0}+F_{x_{u}} \widetilde{M_{q}}-F_{x_{w}} F_{z_{u}}\right)\right]\left[F_{x_{u}}\left(F_{z_{w}} \widetilde{M_{q}}-\widetilde{M_{w}} u_{0}\right)\right.$

$$
\begin{aligned}
& \left.+F_{x_{w}}\left(-F_{z_{u}} \widetilde{M_{q}}+\widetilde{M_{u}} u_{0}\right)-g \widetilde{M_{u}}\right]<g\left(F_{z_{u}} \widetilde{M_{w}}-F_{z_{w}} \widetilde{M_{u}}\right) \\
& \left(\widetilde{M_{q}}+F_{z_{w}}+F_{x_{u}}\right)+\frac{\left[F_{x_{u}}\left(F_{z_{w}} \widetilde{M_{q}}-\widetilde{M_{w}} u_{0}\right)+F_{x_{w}}\left(-F_{z_{u}} \widetilde{M_{q}}+\widetilde{M_{u}} u_{0}\right)-g \widetilde{M_{u}}\right]^{2}}{\left(\widetilde{M_{q}}+F_{z_{w}}+F_{x_{u}}\right)}
\end{aligned}
$$

Persamaan (10) - (13) menunjukkan bahwa faktor yang berpengaruh pada kestabilan persamaan gerak longitudinal adalah momen aerodinamik, kecepatan linear, gaya, percepatan gravitasi, dan gangguan. Dalam kondisi nyata, kriteria kestabilan roket dipengaruhi oleh kecepatan roket, gaya, dan momen [2]. Selain itu terdapat gangguan dalam analisis gerak roket yang berpengaruh pada gaya dan momen roket [2]. 
Selanjutnya, analisis bifurkasi untuk persamaan gerak longitudinal pada Persamaan (5) dapat dilihat dari sifat kestabilan titik ekuilibrium. Dari Persamaan (12) diperoleh parameter bifurkasi $r$, dengan nilai $r$ sebagai berikut.

$$
r=F_{z_{w}} \widetilde{M_{u}}-F_{z} \widetilde{M_{w}}
$$

Dari Persamaan (14) diketahui bahwa jika $r<0$, maka titik ekuilibrium persamaan longitudinal bersifat stabil. Di sisi lain, jika $r>0$, maka titik ekuilibrium persamaan longitudinal bersifat tidak stabil. Selanjutnya, simulasi numerik dilakukan untuk melihat ketidak-ekuivalenan secara topologis. Simulasi numerik tersebut dapat dilihat pada Gambar 2.

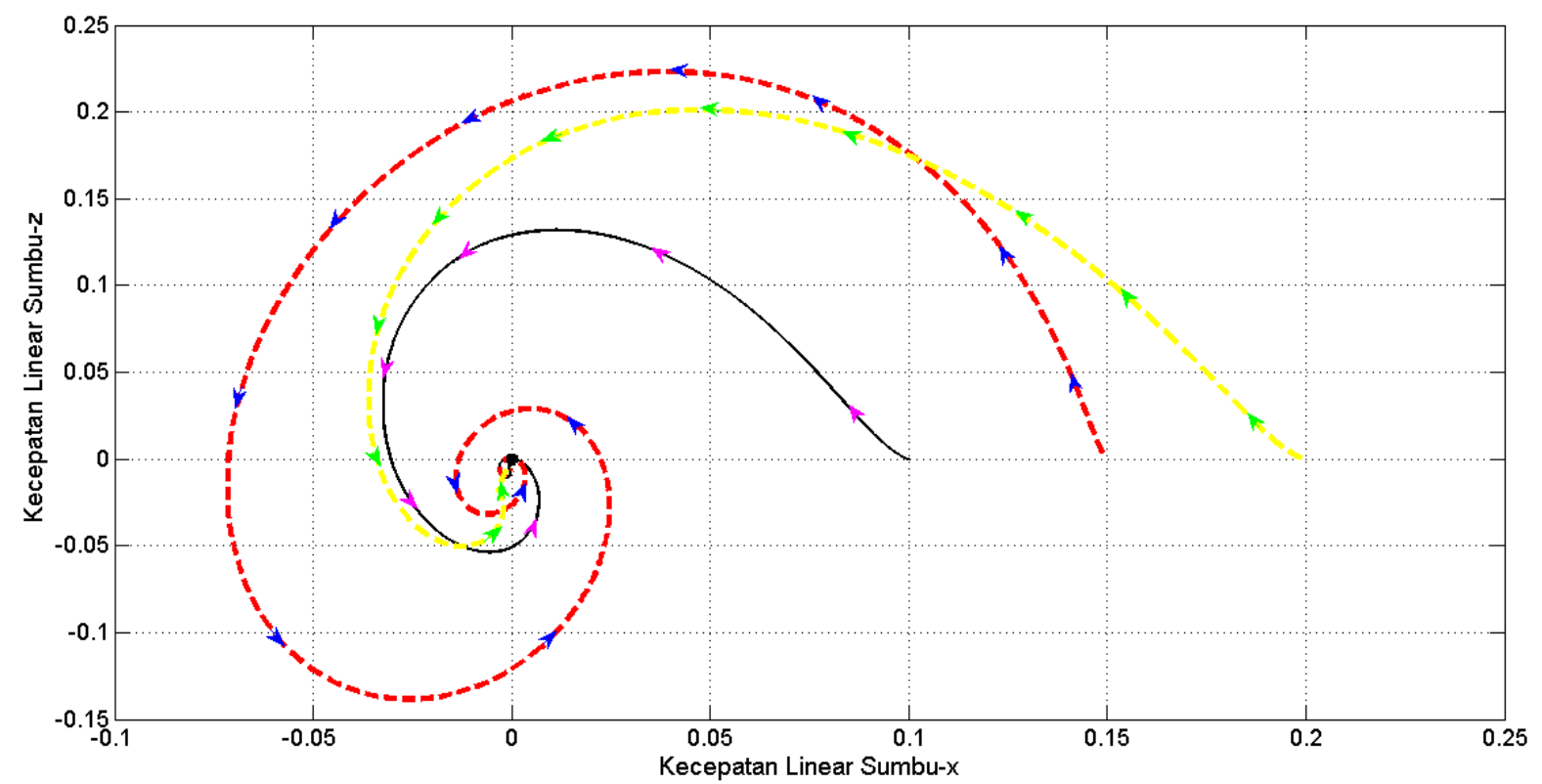

Gambar 2. Potret fase untuk $r<1$

Gambar 2 menunjukkan bahwa untuk $r<1$, jika diambil sebarang nilai awal, maka dalam waktu $t$, solusi akan mendekati titik ekuilibriumnya, sehingga dapat dikatakan bahwa titik ekuilibrium persamaan gerak longitudinal bersifat stabil. Hal ini memiliki interpretasi bahwa sistem gerak roket bersifat stabil. Dengan kata lain, sistem kendali roket dapat bekerja dengan baik. Jenis titik ekuilibrium pada Gambar 2 disebut titik ekuilibrium spiral. Selanjutnya, potret fase untuk $r>1$ dapat dilihat pada Gambar 3 .

Gambar 3 menunjukkan bahwa untuk $r>1$, jika diambil sebarang nilai awal, maka dalam waktu $t$, solusi akan menjauhi titik ekuilibriumnya, sehingga dapat dikatakan bahwa titik ekuilibrium persamaan gerak longitudinal bersifat tidak stabil. Hal ini memiliki interpretasi bahwa sistem gerak roket bersifat tidak stabil. Dengan kata lain, sistem kendali roket belum bekerja dengan baik. Jenis titik ekuilibrium pada Gambar 3 adalah titik ekuilibrium spiral dan titik ekulibrium sadel. Ketidak-ekuivalenan secara topologis dapat dilihat dari Gambar 2 dan Gambar 3. 


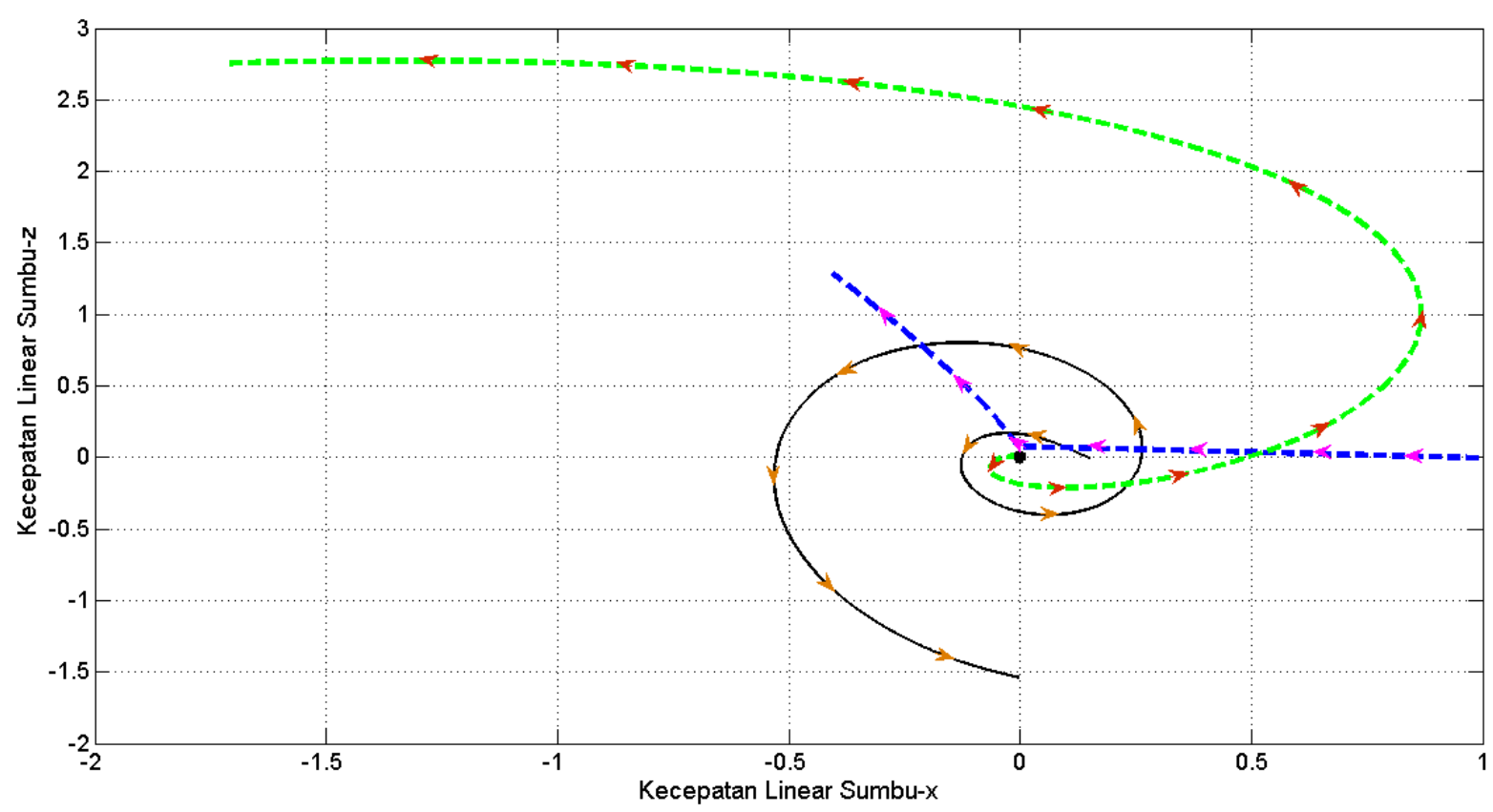

Gambar 3. Potret fase untuk $r>1$

\section{Kesimpulan} berikut.

1. Parameter bifurkasi $r$ menunjukkan ketidakekuivalenan secara topologis dalam hal kestabilan titik ekuilibrium yang ditunjukkan pada gambar potret fase. Jika $r<0$, maka titik ekuilibrium persamaan longitudinal bersifat stabil. Di sisi lain, jika $r>0$, maka titik ekuilibrium persamaan longitudinal bersifat tidak stabil.

2. Kestabilan titik ekuilibrium ini memiliki interpretasi kestabilan sistem gerak roket. Jika $r<0$, maka sistem gerak roket bersifat stabil. Di sisi lain, jika $r>0$, maka sistem gerak roket bersifat tidak stabil.

\section{Daftar Pustaka}

[1] Husnul, A., et al.. (2010). Stucture and Mechanic DIV. LAPAN. Bogor.

[2] Subchan, et al.. (2012). Analisis Kestabilan Persamaan Gerak Roket Tiga Dimensi Tipe RKX-Lapan. Prosiding Seminar Nasional Matematika dan Pendidikan Matematika FMIPA UNY Yogyakarta T-15, pp. 139-148.

[3] Nelson, R.. (1998). Flight Stability And Automatic Control. MCGraw-Hill. USA.

[4] Anton, H.. et al.. (2010). Elementary Linear Algebra Tenth Edition. John Wiley and Sons, Inc. New York.

[5] Olsder, G. J., et al.. (2003). Mathematical Systems Theory Second Edition, Delft University Press. Netherlands.

[6] Perko, L.. (2001). Differential Equations and Dynamical Systems Third Edition. Springer-Verlag. New York.

[7] Kuznetsov, Y. A.. (1998). Elements of Applied Bifurcation Theory Second Edition. Springer. New York.

[8] Verhulst, F.. (1990). Nonlinear Differential Equations and Dynamical Systems. SpringerVerlag. Germany. 
[9] Wiggins, S.. (2003). Introduction to Applied Nonlinear Dynamical Systems and Chaos Second Edition. Springer. New York.

[10] Pujiyanta, A.. (2007). Komputasi Numerik dengan Matlab. Penerbit Graha Ilmu. Yogyakarta. 